\title{
A expressão de plural em Português Huni-Kuin: um exame dos sintagmas nominais ${ }^{1}$
}

\author{
Plural marking in Huni-Kuin Portuguese: an analysis of the noun phrases \\ Beatriz Christino², Amanda de Matos Silva ${ }^{3}$
}

Gostaríamos de agradecer aos dois pareceristas ad-hoc pelas preciosas sugestōes e ressaltar que as falhas que ainda persistem são de nossa total responsabilidade.

Professora-Adjunta III do Departamento de Letras Vernáculas da Faculdade de Letras da Universidade

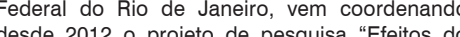
contato linguísico: aspectos morfosintáticos do Português Huni-Kuin". Esse projeto contou com financiamento da FAPERJ (processo E-26/ $111.344 / 2013)$ e teve resultados publicados sob a forma de um capitulo do livro Language Contac: Mobility, Borders and Urbanization, organizad: pela Cambrorontze lzabella Mozilo e publicado in Huni-Kuin Portuguese") Em 2015, atuou como editora convidada da revista Papia 25/1 para a seção 'Línguas indígenas em contato'.

-mail: bpchristino@yahoo.com.br

Desde 2014, vem atuando como pesquisadora de iciaçáo Clentifica vinculada ao projeto "Efeitos do Portug îs Huni-Kuin" subprojeto "Descrição e análise da concordânci e número nos sintagmas nominais do Português Huni-Kuin" (contemplado com bolsa da Faperi) sob a orientaçáa de Beatriz Christino.
RESUMO: Este artigo representa a primeira descrição da marcação de plural nos sintagmas nominais em Português Huni-Kuin. Essa variedade linguística faz parte do conjunto de variedades denominadas 'étnicas' do PB ou 'Português Indígena' e corresponde à segunda língua do povo HuniKuin, que habita a região fronteiriça entre o Brasil e o Peru e, especificamente, terras indígenas localizadas no Alto Juruá e Purus. Esse povo, falante de uma língua da família Pano, considera-se bilíngue e bicultural e, em consequência disso, o Português Huni-Kuin espelha e veicula tal identidade. Com base em referenciais teóricos e metodológicos da sociolinguística quantitativa aplicados a uma análise atomística, são identificadas tendências gerais na marcação de plural nos sintagmas nominais em Português Huni-Kuin, como o papel preponderante da classe morfológica e da saliência fônica. Paralelamente, são abordados também processos que ocorrem com muito pouca frequência, mas podem ser reveladores de processos de transferência estrutural da primeira língua, como a marcação expressa de plural exclusivamente na extremidade da direita dos sintagmas nominais e a combinação de um núcleo nominal no singular com um possessivo no plural, vinculado a um possuidor extra-constituinte de natureza coletiva. Palavras-chave: Português Indígena; Variedades de contato; Marcação de plural.

ABSTRACT: This work presents the first description of the plural marking in Huni-Kuin Portuguese noun phrases. This linguistic variety is part of the group of varieties known as 'ethnical' varieties of Brazilian Portuguese or 'Indigenous Portuguese', and corresponds to the second language of the Huni-Kuin people, that inhabits the border region between Brazil and Peru, specifically the indigenous reservations located in the Upper Juruá and in the Purus basin. This people, a Panoan language speaker, consider themselves bilingual and bicultural and, consequently, Huni-Kuin Portuguese mirrors and spreads such identity. Based on theoretical and methodological references of quantitative sociolinguistics applied to an atomistic analysis, we identify general trends in the plural marking in Huni-Kuin Portuguese nominal phrases, such as the preponderant role of the morphological class and of the phonic salience. In parallel, we also approach processes that occur with very little frequency, but can be revealing of first language structural transference processes, like plural-marking in the left end of nominal phrases and singular head nouns associated to plural possessive pronouns, which are indeed related to extra-constituent plural possessors.

KEYwoRDS: Indigenous Portuguese; Contact varieties; Plural marking. 


\section{Introdução}

abidamente, as relações entre contato linguístico e mudança linguística representam um tópico de grande interesse em Linguística. Conforme indicou Winford (2003, p. 5), há uma longa tradição de investigação ligada ao exame da interação entre fatores linguísticos e sócio-históricos em situações de convívio entre falantes de línguas diversas. Nesse campo, em que muitas questões permanecem ainda em aberto, comparações entre variedades de uma mesma língua com diferentes históricos de contato podem vir a fornecer indicações preciosas. Romaine (1995, p. 76, tradução nossa) destacou a relevância dessa multiplicidade de cenários para o aprofundamento dos estudos do contato linguístico:

Ainda há muito progresso a ser feito no que toca à compreensão da contribuição de vários fatores linguísticos e sociais para diferentes tipos de contato linguístico nos níveis individual e das comunidades [...] Existe uma grande vantagem metodológica quando há uma gama de comunidades empregando a 'mesma' língua com diferentes finalidades [...] Isso, ao menos, nos permite algum entendimento com relação à questão de quais fatores apresentam maior impacto num cenário de contato. Em alguns casos, uma língua pode existir em formas pidginizadas ou crioulizadas, numa série de variedades de imigrantes com diferentes graus de vitalidade, assim como em sua forma plena com variações regionais e sociais. Inglês, Espanhol, Árabe e Francês representam tais casos e necessita-se urgentemente de um trabalho comparativo. ${ }^{1}$

\footnotetext{
1 "There is still much progress to be made in understanding the contribution of various social and linguistic factors to different types of language contact at the individual and community level [...] A great methodological advantage exists when there is a range of communities using the 'same' language or different purposes [...] This at least allows us some purchase on the question of which factors in a contact setting have greater impact. In some cases a language may exist in pidgnized or creolized form, in several immigrant varieties with differing degrees of vitality, as well as in its full form with social and regional variation. English, Spanish, Arabic and French represent such cases and comparative work is
urgently needed."
}

Ao lado do Inglês, do Espanhol, do Árabe e do Francês, citados por Romaine, poderia, certamente, figurar também o Português, que se desdobra num conjunto multifacetado de variedades regionais e sociais, em Portugal; entrou como componente na formação de línguas crioulas como o Cabo-Verdiano e o crioulo da Guiné Bissau; passou por um processo de reestruturação parcial que levou à constituição do (também multifacetado) Português Vernacular Brasileiro (cf. HOLM, 2004) e é mantido por comunidades de imigrantes em diversos países, a exemplo da França, dos Estados Unidos, do Japão e do Canadá, assim como tem se tornado a segunda língua de imigrantes que se estabelecem em Portugal ou no Brasil.

Mesmo considerando apenas a realidade brasileira, já nos deparamos com um panorama fortemente marcado pela diversidade. Além das diferenças entre as regiões e da tão marcada variação diastrática, é preciso levar em conta as especificidades das comunidades de imigrantes, as peculiaridades das várias e extensas áreas de fronteira e todo o universo das variedades indígenas de Português Brasileiro. Se, com relação a estas últimas (que englobam tanto variedades empregadas como segunda língua quanto as que representam o veículo principal de expressão de povos que passaram por processos de substituição linguística), muito ainda permanece inexplorado pelos estudos linguísticos, por outro lado, pode-se também reconhecer um progressivo e constante aumento no conjunto das descrições do(s) Português Indígena.

Tomando parte nesse movimento, nosso grupo de pesquisa vem, desde 2012, examinando aspectos da morfossintaxe do Português Huni-Kuin, em busca de identificar (e explicar) especificidades que o diferenciem das variedades que são primeira língua (doravante L1). Nossa intenção, no presente texto, é focalizar a expressão de plural nos sintagmas nominais em Português Huni-Kuin (doravante também PHK). Para contextualizar devidamente a nossa análise, iniciamos abordando traços linguísticos e extralinguísticos que marcam variedades de Português-Indígena (na seção 2). 
Na sequência, procuramos fornecer algumas informações de cunho etnográfico sobre os Huni-Kuin, sobretudo no que toca à forma como se autodefinem do ponto de vista cultural e linguístico e dos desdobramentos disso na organização do seu sistema próprio de educação formalescolarizada. Partimos, então, para o exame, propriamente, da expressão de plural nos sintagmas nominais do PHK. Nessa investigação, procuramos aliar os referenciais teórico-metodológicos da Sociolinguística Laboviana, a um olhar atento também ao que, nos permitimos chamar de, 'a minoria significativa'. Ou seja, estruturas com pouca expressão do ponto de vista estatístico, mas que são, justamente, aquelas em que se pode entrever a presença de traços das línguas Pano.

\section{0 universo das variedades indígenas de Português Brasileiro}

Semelhantes às variedades indígenas de Espanhol em países como México, Peru e Chile, com que guardam similaridades quanto às condições sóciohistóricas de formação e a sua inserção na atual realidade sociolinguística latino-americana, as variedades indígenas de Português Brasileiro receberam de Rosa Virgínia Mattos e Silva $(1987,1988)$ o significativo título de "România Novíssima". Coordenadora de uma das primeiras equipes de pesquisadores dedicados a registrar e analisar uma variedade indígena de Português Brasileiro, Rosa Virgínia chefiou uma expedição que coletou textos orais em Português Kamayurá no ano de 1968. Com base nesse material, foram reconhecidos diversos traços do Português Kamayurá não compartilhados com as variedades populares de PB empregadas como primeira língua, a exemplo da variação livre entre consoantes surdas e sonoras; da inexistência de distinção de timbre para as vogais médias tônicas (pronunciadas exclusivamente como abertas, seguindo o modelo do sistema fonológico Kamayurá) e da ausência de formas verbais específicas para a 1a pessoa do singular (cf. MATTOS; SILVA, 1988).

A regra variável relativa às formas verbais de $1^{\underline{a}}$ pessoa do singular (com valor de aplicação correspondente ao uso de forma exclusiva para a $1^{\underline{a}}$ pessoa do singular, como dormi ou viajo, e não-aplicação equivalente a emprego da forma não-exclusiva, a exemplo de dormiu e viaja) foi também focalizada por Charlotte Emmerich (1984), que registrou a língua de contato no Parque Indígena do Xingu (falada por oito diferentes povos transferidos para lá ${ }^{2}$ ), tendo coletado dados entre 1976 e 1978. Ela enfatizou que se tratava de uma variedade recente, em uso há não mais de quatro décadas e que, em função do contato controlado e seletivo até então na área, não contaria com influência do PB regional, mas teria se constituído a partir da norma culta do eixo Rio-São Paulo falada pelos médicos e outros funcionários do Posto da FUNAI. Comparando falantes de Português do Alto Xingu (doravante também PIX) de diversas idades e com variados graus de interação com os funcionários do posto, Charlotte Emmerich pôde reconhecer sete diferentes faixas de fluência e associar os níveis 6 e 7 (numa escala crescente de domínio das regras do Português) ao que classificou como "depidignização". Ainda de acordo com ela, no estágio 5 de fluência as regras de flexão e concordância do Português começariam a operar.

A documentação do PIX reunida por Charlotte Emmerich serviu de base, ainda, para várias outras análises, como as oito publicadas num número especial da revista Papia de 1997. Naquele conjunto de artigos, havia um exame da concordância variável de gênero (cf. LUCCHESI; MACEDO, 1997); uma abordagem do desenvolvimento do sistema verbal de tempo, modo e aspecto (cf. FRANÇA, 1997); uma análise da presença/ausência das preposições a, para, de, com e em (cf. GOMES, 1997), assim como

2 Nomeadamente, pelos Aweti, Kuikuro, Trumai, Yawalapiti, Kamayurá, Kalapalo, Waurá e Mehinaku (cf. EMMERICH, 1984). 
investigações de fenômenos fonológicos variáveis (cf. MOLLICA, 1997; PAIVA, 1997) e de aspectos discursivos do Português Xinguano (cf. BAIÃO, 1997; BRASIL, 1997). Em "Processos variáveis e aquisição de preposição", Christina Abreu Gomes aborda igualmente o emprego das preposições no PIX e fornece informações complementares às de seu artigo presente na Papia IX (cf. GOMES, 1997).

Também Alzira Macedo, parceira de Dante Lucchesi no artigo sobre a concordância de gênero no número especial de Papia, dedicou outros trabalhos ao exame do Português Xinguano, como evidencia o volume em sua homenagem organizado por Maria Cecília Mollica e Mário Eduardo Martellota no ano 2000. Ali, encontram-se os textos "Discourse markers in the Portuguese of the Upper Xingu" e "Pidginization and depidginization in the Portuguese of the Upper Xingu". O primeiro deles arrola um conjunto de características daquela variedade que concretizam o(s) processo(s) de reestruturação responsáveis por sua formação.

O Português Xinguano é um exemplo de como uma comunidade inteira vem passando por um processo consideravelmente recente e rápido de contato linguístico com consequente reestruturação. Com falantes de línguas tão diferentes aprendendo Português, a hibridização terciária ocorreu quando o Português foi usado para comunicação intertribal. Devido a essas condições, a variedade que estamos denominando aqui Português do Xingu exibe vários traços típicos de pidginização, tais como ausência de artigos e preposições, ausência de concordância de pessoa, número e gênero, emprego não-padrão de tempo e aspecto, ausência de cópula, assim como um uso peculiar das repetições, para mencionar apenas os aspectos mais salientes (MACEDO, 2000, p. 85 - tradução nossa). ${ }^{3}$

\footnotetext{
3 "Xingu Portuguese is an example of how an entire community has been going through a fairly recent and rapid process of language contact with consequent restructuring. With speakers of so many different communication. Due to these conditions, the variety that we are here calling Xingu Portuguese exhibits various traits typical of pidge condion, such as varion, number repetitions, to mention only a few of the most salient aspects." (MACEDO, 2000, p. 85).
}

Como torna claro o uso do termo "pidginização", os fenômenos mencionados por Alzira Macedo representam processos de simplificação morfossintática e sintática associáveis a universais de aquisição de L2. Não por acaso, boa parte deles surge de modo recorrente em descrições de variedades de Português Indígena. A frequente omissão de artigos, por exemplo, marca presença igualmente na caracterização que Aikhenvald (2003, p. 317) faz do Português dos Tariana, povo cuja primeira língua integra a família Aruak, mas compartilha traços areais com as línguas Tukano na área linguística da bacia do Uaupés. No trabalho de Aikhenvald, no entanto, há, ainda, referências a processos de transferência estrutural. Ela destaca, aliás, que "a principal característica do discurso em Português produzido espontaneamente [pelos Tariana] é uma tentativa de encontrar um equivalente para distinções gramaticais encontradas nas línguas do Vaupés" (AIKHENVALD, 2003, p. 313, tradução nossa) ${ }^{4}$, ou, mais precisamente, a busca por correspondentes para o sistema de evidenciais constituído no Tariana em função do contato frequente e prolongado entre os Tariana e falantes de Línguas Tukano.

Ferreira (2005), em seu exame da variante étnica ${ }^{5}$ dos Parkatejê, indica que em muitos contextos não se faz a concordância de gênero ou acontece uma generalização do masculino, assim como se verifica com frequência a ausência de forma verbal exclusiva para a $1^{\underline{a}}$ pessoa do singular, especialmente na "forma perfectiva do passado" (cf. FERREIRA, 2005, p. 18). A pesquisadora destacou que apenas $10 \%$ dos Parkatejê são, atualmente, fluentes em sua língua originária, pertencente ao chamado "complexo dialetal Timbira”, vinculado à família Jê. Seu trabalho de campo, realizado

4 "the main characteristic of spontaneously produced discourse in Portuguese [by the Tariana] is an attempt to find an equivalent for grammatical distinctions found in the languages of the Vaupés".

5 Conforme aponta Ferreira (2005, p. 6), a denominação "variante étnica” foi proposta por Silvia Braggio em um trabalho de 2001. 
nas duas aldeias Parkatejê, localizadas no município de Bom Jesus do Tocantins (Sudeste do Pará), revelou, ainda, que os falantes mais velhos -que permanecem empregando o Parkatejê - falam Português operando uma substituição sistemática dos fonemas sem correspondente em sua língua materna. Dessa maneira, oclusivas sonoras são transformadas em surdas e vice-versa, acarretando formas como (1) [kra'vatu], por "gravado" e (2) ['peyu], por "feio" (FERREIRA, 2005, p. 10).

Levando em consideração 192 textos escritos e 5 horas e 22 minutos de gravação, obtidos junto a 45 alunos que participavam do $10^{\circ}$ Módulo da Escola Timbira ${ }^{6}$, Amado (2015) traça um retrato do que denomina "português étnico dos povos Timbira". Dentre os aspectos levantados por ela, pode-se reconhecer (novamente) a ausência de concordância de gênero, perceptível em estruturas como (3) "o meu professora" e (4) "a noite inteiro" (cf. AMADO, 2015, p. 109-110). À semelhança do que se observa no artigo de Ferreira (2005), são tematizadas as adaptações à fonologia do Timbira, que incluem a distribuição de modo aleatório dos traços [+voz] e [-voz] nas consoantes e a tendência à supressão da última vogal átona das palavras portuguesas paroxítonas, refletindo a preferência Timbira por sílabas fechadas com coda em consoante e padrão acentual oxítono. Ilustram o último processo pronúncias como (5) [e'zist] por "existe", e (6) ['nom] por "nome" (cf. AMADO, 2015, p. 109). No tocante à expressão do plural, Amado (2015) registra a possibilidade, em Português Timbira, de se acrescentar o morfema de pluralidade na extremidade da direita dos sintagmas nominais (descrita por ela como a "segunda posição dos sintagmas nominais").

${ }^{6}$ De acordo com Amado (2015), o grupo era composto por 24 alunos do povo Krahô, 7 alunos do povo Apãniekrá, 5 alunos do povo Pykobjê, 5 alunos do povo Ramkokamekrá, 2 alunos do povo Krinkati
e 2 alunos do povo Apinajé. O projeto "Escola Timbira", segundo ela, consistiu num "projeto de educação indígena organizado pelo Centro de Trabalho Indigenista (CTI) em parceria com a FUNAI e as secretarias de educação do estado do Maranhão e do Tocantins de 2000 a 2006 " (AMADO, 2015,
p. 107). Seu objetivo era formar alunos, de 15 a 25 anos, no Ensino Fundamental II.
É o que se pode notar em (7) “o serra bonitos" e (8) “da famílias” (AMADO, 2015, p. 109).

Em sua análise da concordância verbal e nominal na escrita em Português-Kaingang, Christino e Lima e Silva (2012) já haviam apontado a existência de estruturas com marcação de plural exclusivamente no último elemento do sintagma nominal. Sintagmas com configurações similares às de (9) "o cemitérios" e (10) "no vídeos", levaram as autoras a postular a hipótese de que a marcação expressa de plural nos elementos mais à direita do sintagma tenha ligação com uma característica do Kaingang (língua da família Jê falada nos estados do Rio Grande do Sul e Santa Catarina, aparentada com o Timbira): constituir-se como uma língua de cabeça à direita, em que a marcação das categorias morfossintáticas se dá na porção direita dos sintagmas nominais (cf. CHRISTINO; LIMA e SILVA, 2012, p. 425). Além disso, elas puderam observar que, a exemplo das demais variedades indígenas do PB, o Português-Kaingang escrito apresenta concordância variável de gênero (cf. CHRISTINO; LIMA e SILVA, 2012, p. 423).

Os trabalhos de Maher $(1996,1998)$, desenvolvidos junto a professores indígenas de nove grupos étnicos distintos do estado do Acre, abarcaram o funcionamento sociopragmático particular do que ela chamou de "Português Índio". Embora, no tocante a elementos da cultura interacional tenha sido possível reconhecer um comportamento comum a todo grupo, Maher teve todo o cuidado de explicitar o seu recorte e de advertir: "Falar de um Português Índio é, de um certo modo, uma generalização: mais correto seria falar em Português Apurinã, Português Kaxinawá, Português Shawãdawa, etc... [sic] Cada uma destas variedades tem, certamente, a sua especificidade" (MAHER, 1996, p. 212). Resultado, em grande parte, de processos de transferência estrutural de traços das diversas L1, esse caráter único de cada variedade de Português Indígena foi sublinhado pelo Referencial Curricular Nacional para as Escolas Indígenas: 
Os povos indígenas têm, cada um deles, o seu modo próprio de falar a língua portuguesa. Esses modos de falar o português têm, quase sempre, marcas muito específicas da língua de origem do povo em questão: no vocabulário, na gramática, na pronúncia. Esses modos de expressão devem ser respeitados na escola e fora dela, já que também são atestados de identidade indígena (MEC, Referencial Curricular Nacional para as Escolas Indígenas, 1998, p. 114).

Nos campos da morfossintaxe e sintaxe, essas "marcas muito específicas" podem assumir a forma de sentenças construídas segundo padrões sintáticos estranhos ao Português L1, revelando, por exemplo, ordem sintática SOV, conversão de preposições em posposições ou adoção da ordem genitivonome. Analisando redações de professores indígenas em formação, Maia (2005) pôde identificar cada um desses processos, patentes em trechos como (11) "O nosso povo com mais facilidade a cultura do branco dominou", que segue o padrão SOV; (12) "a voz aberta com”, atestando a transformação de "com" em posposição e (13) "O povo o costume está alterado hoje”, em lugar de "o costume do povo" (MAIA, 2005 p. 59, p. 61). O povo Dâw, falante de uma língua da família Maku e habitante das margens do Rio Negro (AM), acrescenta a preposição "para" aos constituintes em função de objeto direto em sua variedade de Português. Muito possivelmente, foi estabelecida uma vinculação entre esse elemento (por conta, inclusive, de seu valor de marca de dativo no sistema do Português) e o morfema -uy', de afetado, de expressão obrigatória junto a objetos diretos em Maku?

Se, de um lado, cada variedade de Português Indígena tem, indiscutivelmente, seu caráter particular, combinando influências das variedades L1 regionais e traços associáveis a mecanismos de transferência estrutural, de outro, é preciso não esquecer que, assim como qualquer outra variedade linguística, essas variedades étnicas estão muito longe de se revelar um todo homogêneo, monolítico. Como já frisou Christino (2015a), as variedades

\footnotetext{
${ }^{7}$ Agradeço, muito especialmente, a Valteir Martins por ter me fornecido essa informação em comunicação pessoal.
}

indígenas de PB tomam parte em panoramas sociolinguísticos intensamente multifacetados, em que questões de gênero e/ou geracionais desempenham papel de extrema relevância. Demandando estudos de cunho etnográfico em profundidade, essas variedades inserem-se numa gama ampla e bastante diversificada de situações, que se associam a registros bastante diferenciados no que toca ao grau de formalidade e natureza dos gêneros textuais. Um mesmo falante pode, por exemplo, se comunicar com profissionais nãoindígenas da saúde, da assistência social, da área da educação ou com autoridades religiosas; realizar compras no centro de comércio local; ser um dos responsáveis pela produção de material didático para ensino de Português L2; escrever documentos para prestação de contas de repasses de verbas e/ou trabalhos acadêmicos (em especial, para aqueles que são alunos de cursos universitários); passar recados em emissoras locais de rádio, etc.

Em muitos contextos, variedades de Português Indígena servem, ainda, como língua veicular interétnica. É o caso, particularmente, do Português Huni-Kuin, que focalizaremos mais de perto, usado não só para comunicação em esferas supra-regionais (como as alianças de lideranças indígenas para reinvindicação de direitos junto a autoridades nacionais), mas também com os vizinhos Ashaninka, falantes de uma língua Aruak. Como veremos na seção seguinte, o Português Huni-Kuin integra o conjunto dos elementos definidores da identidade Huni-Kuin.

\section{Português Huni-Kuin e identidade bicultural}

Nas regiões do Alto Juruá e do Purus, nos dois lados da fronteira BrasilPeru, vivem os Huni-Kuin (autodenominação que corresponde a 'humanos autênticos'), também conhecidos como Kaxinawá (ou 'povo do morcego', título recebido de inimigos históricos) e que somam cerca de doze mil e quinhentos indivíduos. Em território brasileiro, vivem em doze terras 
indígenas homologadas nos municípios acreanos de Marechal Thaumaturgo, Tarauacá, Feijó, Jordão, Manuel Urbano e Santa Rosa. Como os demais povos indígenas da região, os Huni-Kuin foram escravizados por seringalistas durante um largo período (que vai do chamado ciclo da borracha até meados dos anos 1980) e tiveram sua língua e cultura duramente perseguida.

Com o apoio da Comissão Pró-Índio do Acre, tornaram-se autores de materiais que retratam a história segundo sua perspectiva, marcada por uma divisão em quatro grandes períodos: tempo das malocas, tempo das correrias, tempo do cativeiro e tempo dos direitos. $\mathrm{O}$ primeiro deles corresponde à toda fase anterior ao contato com o não indígena, em que as habitações - as chamadas "malocas" - eram coletivas. Na virada do século XIX e décadas iniciais do $\mathrm{XX}$, primeiros anos do contato, os seringalistas organizavam expedições de expropriação das terras indígenas, que promoviam terríveis massacres e recebiam o nome de "correrias". 0 tão cruel quanto duradouro "tempo do cativeiro", marcado pela escravidão imposta pelos "patrões" e abandono forçado da cultura tradicional, tem lugar em muitos relatos dos Huni-Kuin quando rememoram sua infância e juventude. As palavras de Remilde Henrique, um dos líderes da Aldeia Vida Nova, reconstroem esse momento triste de submissão aos preconceituosos patrões e obrigação de dedicação exclusiva à extração da borracha.

eu comecei a cortar seringa também... de tempo de cati... cativeiro, né... tempo de cativeiro [...] a seringa... eu sempre já cortava a seringa com ... junto com meu pai, eu era pequeno... tempo eu... eu cortava mais ele [e] meu irmão [...] ele sempre trabaiava cortando seringa, nós saía de madrugada, quando tá chovendo ou num chovendo... tem que trabaiar, né... se você trabaiar só no roçado ou caçada... os patrão num cons... ele não... aceita isso que... ele faz: "é preguiçoso, os índio são preguiçoso!" [...] diz assim: "num trabaiô nada!"... aquele que num colocou roçado ou se... só fazendo borracha... aquele... falava: "aquele é trabaiador... ele tira saldo tanto", né [...] e eu trabaiava só no seringal (REMILDE HENRIQUE, depoimento registrado durante trabalho de campo em janeiro de 2014).
O tempo "dos direitos" só chegou em consequência de um movimento aguerrido, organizado e incansável das lideranças indígenas. Parte das conquistas, que incluem o reconhecimento e homologação de terras indígenas, encontram-se formalizadas na Constituição de 1988. Para ficar em um exemplo especialmente significativo, pode-se ler no Capítulo III "DA EDUCAÇÃO, DA CULTURA E DO DESPORTO/SEÇÃO I - "DA EDUCAÇÃO”: "O ensino fundamental regular será ministrado em língua portuguesa, assegurada às comunidades indígenas a utilização de suas línguas maternas e processos próprios de aprendizagem." (Art. 210, § 2oㅡ. Com amparo legal e apoio técnico de instituições como a Comissão Pró-Índio do Acre, os Huni-Kuin desenvolveram seu sistema formal próprio de educação, fundamentalmente bilíngue e bicultural. Dessa forma, as escolas nas aldeias passaram a refletir a identidade Huni-Kuin, que busca combinar num equilíbrio difícil e delicado - a preservação da cultura tradicional, o domínio dos meios tecnológicos atuais e a participação em elementos da cultura majoritária. Todos esses universos marcam presença na definição de ensino Huni-Kuin exposta por Ibã Sales, artista plástico, pajé, pesquisador e educador (segundo a nossa, claramente falha e etnocêntrica, tentativa de categorizá-lo):

Nosso ensino é diferente de outras escolas porque a educação de cada povo é diferenciada das outras. Diferencia quando ensina a ler e escrever na nossa própria hãtxa kuin ensina o período da colheita dos plantios, a pescaria, a caçada, a construção da nossa moradia, o artesanato e a nossa medicina tradicional, a nossa música de cipó e a festa de katxa nawa, mariri. Ensina a defender a nossa terra demarcada. Ao mesmo tempo nossa escola se aproxima de todas as escolas pelos métodos pedagógicos de ensinar a ler e escrever que são parecidos com o de outras escolas. Ensina Língua Portuguesa, matemática, História, Ciência, Geografia, ensina a falar e escrever bem e trazer sempre os novos conhecimento (SALES, Ibã. Post publicado em seu perfil no Facebook em 31 de julho de 2013). 
Com frequência, o ensino em Português e em hantxa kuin (nome que os Huni-Kuin dão a sua língua e pode ser traduzido como 'a língua autêntica'), converte-se num elemento definidor do modo (atual) de ser dos Huni-Kuin. Durante um curso de formação de agentes de saúde promovido pela Comissão Pró-Índio do Acre, Ivanildo Paulino Kaxinawá declarou: “Os índio entendemos o língua do nauá que tão aprendendo junto. É... os índio tão aprendendo com dois língua: a língua de que nosso mesmo, a língua de português." Assim como se percebem bilíngues, os Huni-Kuin também pretendem unir a medicina tradicional àquela dos profissionais formados nas universidades e tomar parte tanto em festas próprias de sua comunidade (o katxanawa e o mariri) como da cultura regional/nacional. Sua religiosidade, igualmente, mostra-se uma complexa combinação de elementos originariamente HuniKuin e releituras muito particulares dos preceitos e rituais cristãos. No campo da medicina, são reveladoras as palavras de Aldenir Kaxinawá, agente de saúde da Aldeia Cruzeirinho:

eu quero fazê no meu pesquisa como medicina tradicional pra fazê cura no meu povo, minha comunidade e todo terra indígena [...] então meu pensamento é assim como meu formação como agente saúde, né, como até como nós... como nós equilibrado como huni kuin, nauá, como em português, né? (depoimento gravado durante trabalho de campo em janeiro de 2014).

Há, portanto, um paralelo evidente entre a possibilidade de conciliar a medicina do "nauá" (nesse contexto, o não-indígena) e o conhecimento secular das ervas medicinais, transmitido oralmente pelos pajés, e o emprego do Português Huni-Kuin como língua de comunicação com - e atuação na sociedade não Huni-Kuin.

À semelhança das missas que acontecem na aldeia Glória de Deus, celebradas por um pajé em processo de formação e que incluem cânticos

\footnotetext{
${ }^{8}$ Agradecemos à Comissão Pró-Índio do Acre por nos ter, tão gentilmente, fornecido uma cópia dos registros em áudio deste curso.
}

espirituais da tradição Huni-Kuin, o Português Huni-Kuin apresenta uma feição bastante particular. Alguns de seus traços podem ser vinculados a universais de segunda língua, a exemplo da frequente não-utilização da forma verbal exclusiva para a primeira pessoa do singular (caso de (14) "eu já faz de cura tamém"9 e (15) "eu, pelo menos, assim que eu viu nessas aldeia") e a recorrente ausência de artigos definidos em contextos marcados pela definitude ${ }^{10}$. Outros sugerem processos de transferência estrutural, como o emprego esporádico da ordem sintática sujeito-objeto-verbo ${ }^{11}$. Na próxima seção, procuramos reconhecer traços característicos do PHK em um fenômeno variável em Português Brasileiro que conta com uma longa e sólida tradição de descrição: a expressão de plural nos sintagmas nominais.

\section{A expressão de plural nos sintagmas nominais em PHK}

Desde a introdução da Sociolinguística quantitativa no Brasil, em que desempenhou papel de destaque Anthony Julius Naro (v. OLIVEIRA, 2016), a expressão variável de plural nos sintagmas nominais (presença de marcação expressa de plural $\mathrm{x}$ ausência de marcação expressa) vem se mostrando um objeto de estudo dos mais relevantes. Ainda na década de 1970, realizaram-se as primeiras análises da concordância nominal em variedades do Português Brasileiro segundo esse referencial teórico ${ }^{12}$.

${ }^{9}$ Sempre que não houver indicação explícita de outra fonte, os exemplos em Português Huni-Kuin provêm de gravações de depoimentos espontâneos realizadas em trabalho de campo em janeiro de 2014

${ }^{10}$ Sobre o emprego de artigos definidos em Português Huni-Kuin, cf. Christino (2015).

${ }^{11}$ Ver o item "Considerações Finais - 'a minoria significativa'".

${ }^{12}$ É o caso das dissertações de mestrado de Maria Luiza Braga (A concordância de número no sintagma nominal no triângulo mineiro, de 1977), de Maria Marta Pereira Scherre (A regra de concordâng nominal de uma comunidade de Porto Alegre, de 1979). 
A listagem de trabalhos sobre a concordância nominal de plural presente no Anexo 1 de Naro e Scherre (2006) - que conta com 26 diferentes referências, todas voltadas para variedades L1 do Português Brasileiro nos fornece uma boa medida da importância conferida à questão. Nesse conjunto, a pesquisa de Guy (1981) se tornou uma referência obrigatória, assim como vários trabalhos de Marta Scherre (e, em especial, SCHERRE, 1988). Para Guy (1981), a marcação de plural no Português Brasileiro seria, sobretudo, um fenômeno de estrutura linear. Desse modo, a primeira posição do sintagma nominal se mostraria fundamental para a marcação expressa de plural, enquanto as posições mais à direita se revelariam, progressivamente, menos favoráveis à marcação expressa de plural. Na visão de Scherre (1988), a relação entre posição linear e classe gramatical demanda especial atenção. Além disso, a pesquisadora observou que qualquer classe anteposta ao núcleo do sintagma nominal favorece a marcação expressa de plural, ao passo que, qualquer que seja a classe gramatical posposta ao núcleo, se nota um desfavorecimento da marcação expressa de plural.

Como indicaram, por exemplo, Baxter (2009: 269) e Brandão (2011: 59), hipóteses acerca da(s) origem(ns) de estruturas do tipo as menina esperta estiveram no centro do debate entre "contatistas" e "derivistas", ou seja, entre os que filiam as especificidades do Português Brasileiro ao contato linguístico e ao processo de transmissão linguística irregular, de um lado, e aqueles que reconhecem nesses processos, fundamentalmente, uma continuação da deriva secular do Português, de outro. Para contribuir com esse debate, revelam-se especialmente interessantes as análises da concordância nominal em variedades que representam a segunda língua dos grupos em foco, na mesma medida que aquelas variedades com claro passado de L2. No terreno das variedades características de comunidades quilombolas, Petter e Zanoni (2005) examinaram o processo de variação na marcação de plural, correlacionando-o com a concordância variável de gênero, em regiões do Vale da Ribeira (SP). Considerando a comunidade quilombola de Helvécia (BA), em comparação com o falar dos Tongas de Santomé13, Baxter (2009) levantou os fatores estruturais e sociais que determinavam a expressão da concordância de plural.

Em sua condição de L2 ou de primeira língua de povos que passaram por processos de substituição linguística, as variedades de Português Indígena representam, indiscutivelmente, também um campo privilegiado para estudos dessa natureza. No entanto, ainda são poucas as análises da concordância nominal em variedades indígenas do Português (como a presente em CHRISTINO; LIMA e SILVA, 2012) e, sobretudo, as que se situam no terreno da sociolinguística quantitativa. Com relação à variedade (L2) dos Huni-Kuin, em especial, este artigo corresponde à primeira análise sistemática da expressão de plural nos sintagmas nominais.

Com o apoio financeiro da Faperj, foi realizado, em janeiro de 2014, trabalho de campo nos municípios de Cruzeiro do Sul e Marechal Thaumaturgo, com visita também às cinco aldeias da Terra Indígena Kaxinawá-Ashaninka do Rio Breu ${ }^{14}$. Nesse período, foram gravados depoimentos em Português Huni-Kuin de 33 falantes. A presente pesquisa (pioneira no tema, como indicado logo acima) baseia-se em uma amostra dessa documentação, composta por textos de 16 falantes. Apenas dois colaboradores, nesse grupo, são do sexo feminino, o que se explica por um traço próprio da cultura HuniKuin: tradicionalmente, o papel de receber forasteiros cabe aos homens. No Quadro 1, adiante, encontram-se registradas as faixas etárias recobertas pela pesquisa.

${ }^{13}$ De acordo com a nota de rodapé 3 em Baxter (2009: 270): “Os tongas são os descendentes de africanos contratados, no final do século XIX e durante o século XX, para trabalhar nas grandes rocas de café cacau por períodos de 3 a 5 anos, com contratos renováveis. Os filhos nascidos em São Tomé passaram a ser a propriedade de facto das grandes roças."

${ }^{14}$ Essa temporada de pesquisa de campo conta com as devidas autorizações da FUNAI, vinculadas ao processo FUNAI/MJ no 08620.039933/2014-13. 
Quadro 1 - Distribuição dos colaboradores da pesquisa por faixa etária

\begin{tabular}{|l|c|}
\hline Faixa Etária & Colaboradores \\
\hline Até 30 anos & 4 \\
\hline De 30 a 45 anos & 7 \\
\hline De 45 a 60 anos & 3 \\
\hline Mais de 60 anos & 2 \\
\hline
\end{tabular}

Como aponta o Quadro 1, também no tocante à idade dos colaboradores não foi possível constituir uma amostra completamente equilibrada. Nesse particular, questões culturais tornam especialmente difícil o contato de menores de vinte anos e de idosos com recém-chegados.

A distribuição dos colaboradores da pesquisa no que toca ao nível de escolaridade, por sua vez, aparece documentada no Quadro 2.

Quadro 2 - Distribuição dos colaboradores da pesquisa por nível de escolaridade

\begin{tabular}{|l|c|}
\hline Nível de Escolaridade & Colaboradores \\
\hline Nenhuma & 1 \\
\hline Ensino primário incompleto & 3 \\
\hline Ensino primário completo & 1 \\
\hline Ensino médio incompleto & 3 \\
\hline Ensino médio completo & 2 \\
\hline Ensino superior completo & 6 \\
\hline
\end{tabular}

Se, por um lado, a distribuição por nível de escolaridade representada no Quadro 2 está longe de ser equilibrada, por outro, a presença de seis falantes com ensino superior completo ${ }^{15}$ indica que a amostra contém, inclusive,

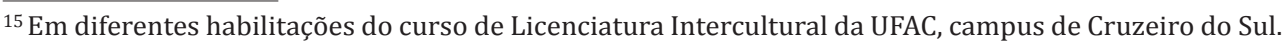

aqueles que conviveram longamente com o Português culto na modalidade escrita.

Um levantamento exaustivo dos sintagmas nominais no plural nos depoimentos dos 16 colaboradores levou à reunião de um corpus com 1079 ocorrências de elementos no plural, considerando-se como aplicação da regra variável a presença de um morfema de plural (o que se nota no primeiro elemento de "essas duas perna aqui") e, analogamente, a sua ausência como um caso de não-aplicação (o que se observa em "perna", terceiro elemento daquele mesmo sintagma nominal). Em 555 ocorrências (ou 51,4\% do total) observou-se a aplicação da regra, enquanto em 524 ocorrências (ou 48,6\% do total) houve a não-aplicação.

Combinando fatores já reconhecidos como relevantes em descrições da expressão de plural nos sintagmas nominais em outras variedades de $\mathrm{PB}$ a outros associados a especificidades do PHK, investigaram-se 13 critérios de análise: Presença/ausência de marca de plural no elemento precedente do sintagma nominal; Núcleo/não-núcleo do sintagma nominal; Plural com ou sem saliência fônica; Fonologia do Singular (terminação em ditongo nasal, terminação em -l, terminação em -r, não-saliente oxítono, não-saliente paroxítono; não-saliente proparoxítono, monossílabo); Posição do elemento em relação à ordem linear do sintagma nominal; Posição em relação ao núcleo do sintagma nominal; Gênero do núcleo do sintagma nominal; Concordância de gênero (expressa/não-expressa); Classe morfológica do elemento; Animacidade do núcleo do sintagma nominal; Humanidade do núcleo do sintagma nominal; Número de elementos do sintagma nominal e Função sintática do sintagma nominal.

Nosso recorte será enfocar, de um lado, aqueles fatores que foram destacados pela análise estatística empreendida com o auxílio do programa Goldvarb X e, de outro, sublinhar os resultados que apontem para aspectos particulares ao PHK. Com relação à posição linear do elemento no sintagma 
nominal, levando em consideração análises como as de Guy (1981) e Scherre (1988), esperávamos encontrar uma tendência à marcação expressa na primeira posição, caso o PHK acompanhasse, em linhas gerais, o Português Popular L1 do Alto Juruá.

Com efeito, da mesma forma que em outras variedades do PB, a estratégia de marcação de plural mais utilizada na amostra analisada de PHK corresponde à marcação de plural expressa unicamente no primeiro elemento do sintagma nominal. Em alguns contextos, inclusive, pôde-se reconhecer uma sobregeneralização do padrão marca de plural no primeiro elemento, em que categorias sem marca de plural na gramática do Português (L1) receberam o morfema $-s$. Tal processo foi verificado tanto em contextos com quantificadores (como em (16) e (17)), quanto em contextos contendo numerais (a exemplo de (18)): (16) "cadas aldeia trabalhando assim, né?"; (17) "sem comê carne, nem tando com tudos fome" e (18) "vinte e quatos aluno que eu tenho nesse ano". Algumas ocorrências de 'tudos' + 'nome', no entanto, parecem ser melhor explicadas em função da concordância variável de gênero em PHK. Nesse conjunto, enquadra-se (19) "pra nóis colocá a nossa aldeia tudos comunidade tudos terra indígena"16.

Nossa hipótese, no que toca à classe gramatical, antevia uma tendência ao desfavorecimento de marcação expressa de plural nos substantivos, que alcançasse uma porcentagem maior do que nos adjetivos e possessivos, contrapondo-se a um favorecimento expressivo no caso dos artigos (na linha do que observou SCHERRE, 1988). No entanto, a clara predominância da estrutura com marca exclusivamente no primeiro elemento acarreta uma sobreposição entre os fatores 'classe morfológica' e 'posição' (o que havia sido anteriormente destacado por SCHERRE, 1994). Isso explica que, na rodada identificada como a melhor pelo Goldvarb X, o grupo 'classe

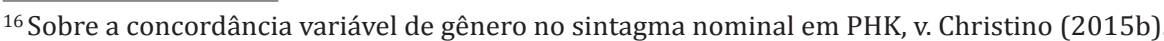

morfológica' tenha sido o primeiro selecionado e o grupo 'posição' tenha sido o segundo, ao mesmo tempo que a lista dos fatores eliminados pelo processo de stepping-down seja encabeçada justamente pelo fator 5 - 'Posição do elemento em relação à ordem linear do sintagma nominal'. Nas Tabelas 1 e 2 abaixo, pode-se verificar os pesos relativos determinados para esses fatores na melhor rodada.

Tabela 1- Peso relativo - aplicação do fator 'classe morfológica'

\begin{tabular}{lcc}
\hline Classe Morfológica & Plural Expresso & Plural Não Expresso \\
Pronome demonstrativo & .91 & .09 \\
Artigo & .88 & .12 \\
Pronome possessivo & .82 & .18 \\
Preposição + artigo & .71 & .29 \\
Quantificador & .61 & .39 \\
Pronome indefinido & .53 & .47 \\
Nome & .28 & .72 \\
Adjetivo & .26 & .74 \\
\hline
\end{tabular}

Assim como nas observações de Scherre (1988), os maiores pesos relativos vinculados à expressão de plural ligam-se a classes morfológicas que ocupam a primeira posição no sintagma, com destaque para o pronome demonstrativo (.91) e o artigo (.88). Vale apontar, ainda, que a presença de uma preposição diante do artigo torna menos provável a expressão do plural, que alcançou um peso relativo de .71. Por conta da pouca quantidade de dados com tal configuração, não pôde ser notado efeito semelhante para as estruturas do tipo 'preposição + pronome demonstrativo' e 'preposição + pronome indefinido', que acabaram por ser englobadas, respectivamente, no conjunto dos dados de 'pronome demonstrativo' e de 'pronome indefinido'.

Análises anteriores de peculiaridades do PHK nos levaram a examinar em separado os artigos antecedidos por preposição. Christino (2015) constatou 
que a presença de preposição influenciava a distribuição e, em especial, a omissão ou sobreutilização de artigos definidos em PHK. Trabalhando com uma amostra de PHK diversa da analisada aqui ${ }^{17}$, ela identificou ocorrências como (20) e (21): (20) "a miração como surgia pé entrando dentro do nós"; (21) "pa cuidá da floresta, das caça, des pesca”. Naquele momento, (21) era o único exemplo da combinação preposição + morfema - $s$ de plural e podia até ser tomada como uma hápax legomena ou uma idiossincrasia do locutor. O corpus agora examinado, que inclui (22) "projeto do artesanato des conta", afastou essa possibilidade.

Voltando-se às informações inscritas diretamente na Tab. 1, convém sublinhar que as duas categorias morfológicas com menor probabilidade de conter o morfema de plural foram a de 'adjetivo' (peso relativo de .26) e a de 'nome' (peso relativo de .28). Mais uma vez, nota-se a associação entre classe morfológica e posição, uma vez que adjetivos e nomes muito raramente ocupam a primeira posição do sintagma nominal. Ainda que estes dados tenham sido descartados pela rodada stepping-down do Goldvarb X, atentemos para a relação que se estabelece entre posição do elemento no sintagma nominal e presença da marca de plural.

Tabela 2 - Peso relativo - aplicação do fator "posição no Sintagma nominal"

\begin{tabular}{lcc}
\hline Posição no & Plural Expresso & Plural Não Expresso \\
Sintagma Nominal & .61 & .39 \\
Primeiro & .61 & .39 \\
Quarto & .51 & .49 \\
Terceiro & .41 & .59 \\
\hline Segundo & & \\
\hline
\end{tabular}

${ }^{17}$ Agradecemos, muito especialmente, à Comissão Pró-Índio do Acre e ao professor da UFAC-Cruzeiro do Sul e documentarista Amilton Mattos por terem fornecido as gravações de PHK que serviram de material de análise na primeira fase do projeto de pesquisa "Efeitos do contato linguístico: aspectos morfossintáticos do Português Huni-Kuin".
A Tab. 2 documenta um padrão de distribuição do peso relativo da aplicação da regra 'presença de marca expressa de plural'/ posição no sintagma nominal que coincide em parte com o reconhecido por Scherre (1994). Considerando dados provenientes de falantes nativos do PB, Scherre constatou que os núcleos na primeira posição eram os mais marcados e, no extremo oposto, colocavam-se os que se encontravam na segunda posição. Nosso corpus de PHK também apresentava os elementos em segunda posição como os menos marcados (com peso relativo de .41), embora não haja uma diferença numérica extremamente significativa entre as várias posições, como se vê na Tab. 2. Enquanto, na análise de Scherre, os núcleos em terceira e quarta posição ocupavam os termos intermediários da escala, os dados do PHK (que levam em conta todos os elementos pluralizáveis dos sintagmas nominais) revelam um peso relativo (.61) idêntico para os elementos na primeira e na quarta posição. Pode-se comparar, também, estes resultados com os obtidos por Scherre (1988). Naquele trabalho, Scherre observou a influência da variável ordem linear, isoladamente, e em combinação com classe gramatical e com presença de marcas precedentes. Em todas os cenários, a primeira posição revelou-se a mais marcada, ficando sempre com índices superiores a .70 de plural expresso. Nesse sentido, pode parecer pouco expressivo o peso relativo de .61 para a primeira posição na amostra de PHK. Acreditamos que esse índice mais baixo se deva à existência em PHK de sintagmas cuja marca expressa de plural se localiza exclusivamente na extremidade da direita dos sintagmas nominais, que serão abordadas logo adiante.

O terceiro fator a ser selecionado pelo Goldvarb X foi 'saliência fônica'. Conforme apontou Brandão (2011, p. 64), o "princípio da saliência fônica" foi proposto por Lemle e Naro (1977) ${ }^{18}$ e indica que as formas de plural

${ }^{18}$ LEMLE, Míriam; NARO, Anthony Julius. Competências básicas do português. Rio de Janeiro: Mobral/ Fundação Ford, 1977. 
apresentando saliência fônica (ou seja, cuja diferença entre singular e plural é marcada por mais traços fonológicos do que apenas a inclusão de - $s$ no plural) tendem a favorecer a marcação expressa de plural, ao passo que as formas sem saliência a desfavorecem. Nossa hipótese, portanto, assumiu essa mesma direção: formas providas de saliência (como "irmãos" e "tradicionais") receberiam mais marcação expressa de plural do que formas sem saliência (do tipo "pesquisas").

De acordo com o que nos mostra a Tabela 3, a marcação expressa de plural foi muito favorecida pela saliência fônica em nossa amostra de PHK, a exemplo do que já havia sido reconhecido na literatura sociolinguística, em trabalhos como Scherre (1988) e Lopes e Scherre (2014). Nesse sentido, Naro e Scherre (2006, p. 111-112) afirmaram:

A variável lingüística denominada saliência fônica por Naro \& Lemle na década de 1970 e levada a cabo por Naro e diversos estudiosos brasileiros até os dias de hoje [...] têm mostrado a pertinência da saliência fônica nos fenômenos de concordância de número no português brasileiro.

Tabela 3 - Peso relativo - aplicação do fator "saliência fônica"

\begin{tabular}{lcc}
\hline Saliência Fônica & Plural Expresso & Plural Não Expresso \\
Com saliência & .78 & .22 \\
Sem saliência & .46 & .54 \\
\hline
\end{tabular}

Fica evidente, na Tabela 3, que as estruturas sem saliência fônica não desencadeiam um efeito claro sobre a marcação de plural em PHK. Dito de outra maneira, os pesos relativos de .46 (para plural expresso) e .54 (para plural não expresso) revelam um padrão muito próximo à neutralidade. Como adiantado acima, não se pode dizer o mesmo para as formas contendo saliência fônica, uma vez que o peso relativo para plural expresso alcançou o significativo índice de .78. Esse número, aliás, é muito próximo do índice de .75 de expressão de plural nos elementos portadores de saliência fônica a que chegou Scherre $(1988,1994)$.

No caso específico do PHK, formulamos a hipótese de que contribuam para essa influência tão patente da saliência fônica na marcação de plural também mecanismos de transferência da L1. As línguas da família Pano não admitem prefixos e têm caráter aglutinante. De forma geral, as palavras dessas línguas são formadas por uma cadeia de sufixos e aqueles de conteúdo mais gramatical, sem os quais os enunciados se tornam agramaticais (como os de tempo, modo, aspecto e força ilocucionária), são os últimos a serem adicionados. Por consequência, tipicamente, é grande o peso fônico na extremidade da direita das unidades lexicais. Achamos plausível que essas características das línguas Pano levem os Huni-Kuin a conferirem especial relevo à presença de saliência fônica em formas do plural em sua variedade de Português. Em PHK, mesmo formas sem saliência fônica no Português empregado por falantes nativos podem assumir uma terminação contendo saliência. Pajeres (presente em (23) e (24)) corresponde a um exemplo recorrente desse processo: (23) "Hoje nós temos os pajeres né, que são criado assim, na aldeia"19 e (24) "Isso é uma troca de saberes, de conhecimento, aonde chegam os pajeres representantes. ${ }^{20 "}$ Embora não tenhamos encontrado ocorrências dessa natureza no corpus que serviu de base a essa análise, pudemos presenciar, durante o evento de lançamento do livro Una Isï Kayawa - O livro da cura do povo Huni-Kuin, no Jardim Botânico do Rio de Janeiro em julho de 2014, um dos autores agradecer, comovido, "a presença de todos voceres".

O caráter aglutinante e sufixal das Línguas Pano aliado à relevância gramatical dos sufixos que se situam na extremidade da direita nessas línguas

${ }^{19}$ Trecho de depoimento do Pajé Ninawá, registrado no vídeo $O$ chamado do novo futuro, disponível no You Tube no endereço https://www.youtube.com/watch?v=e7E570KF27U.

${ }^{20}$ Trecho de depoimento de Itsairu Huni-Kuin durante a Rio +20 registrado por Amilton de Mattos. 
e seu peso fônico, possivelmente, também explicam sintagmas em PHK cuja marcação de plural ocorre exclusivamente na extremidade da direita do sintagma nominal. Mesmo não sendo muito frequentes, é fácil notar que não constituem uma idiossincrasia. Do corpus que ora descrevemos, fazem parte (25) "outro velhos"; (26) "tempo ancestrais"; (27) "muito valores" e (28) "erva medicinais". Por sua vez, o conjunto de textos analisados na primeira fase de nosso projeto de pesquisa continha, entre outros, (29) "nosso arrecurso naturais"; (30) "do meu tradições" e (31) "erva medicinais". A formulação "erva medicinais", em especial, mostra-se recorrente em PHK, sendo tão ou mais comum do que as variantes 'ervas medicinal' e 'ervas medicinais'. É possível, em construções como essas, que o falante de PHK interprete o vocábulo fônico como uma única unidade morfossintática, semelhante às cadeias de sufixos de sua língua materna.

Como se pode facilmente notar, à exceção de (25), todos esses dados indicam uma relação entre expressão do plural na extremidade da direita e presença de saliência fônica, o que parece fortalecer nossas hipóteses quanto à atuação de transferência estrutural da L1.

\section{Considerações finais - 'A minoria significativa'}

$\mathrm{Na}$ intenção de reconhecer particularidades morfossintáticas do Português Huni-Kuin, temos adotado uma abordagem que combina a identificação das tendências gerais nessa variante, sublinhadas pelas análises de natureza estatística, a uma atenção especial a dados poucos frequentes, mas que possam ser vinculáveis a processos de transferência estrutural.

Integram o primeiro grupo - o dos fenômenos com alta incidência e, como tal, reveladores de tendências gerais - a influência da classe morfológica e da saliência fônica na distribuição da marcação expressa de plural em PHK. Fazendo jus ao rótulo de 'minoria significativa', encontram-se os fenômenos pertencentes ao segundo grupo. Nesse último, incluem-se, certamente, ocorrências como (22) "des conta" ou os sintagmas com plural marcado somente na extremidade da direita reproduzidos em (25) a (31).

Estão englobados nesse grupo, ainda, um pequeno conjunto de sentenças do corpus com ordem sintática SOV e, portanto, idêntica àquela que é a canônica nas línguas Pano. É o caso de (32) "ele chamô a macaxeira comê"; (33) "o pessoa nós ajudar" e (34) "fruto pra tem que leva pus pessoa com fome pra eles alimentar". Em (34), o contexto não deixa dúvidas de que "eles" desempenha a função de objeto.

Como uma primeira abordagem da marcação de plural em Português Huni-Kuin, esse trabalho levantou hipóteses, sobretudo no tocante a processos de transferência estrutural, que pretendemos seguir investigando.

\section{Referências}

AIKHENVALD, Alexandra Y. Language contact in Amazonia. Oxford: Oxford University Press, 2003.

AMADO, Rosane de Sá. O português étnico dos povos Timbira. Papia, n. 25, v. 1, p. 103-119, 2015.

BAIÃO, Rosaura de Barros. Os marcadores discursivos no Português de Contato. Papia, n. 9, p. 72-79, 1997.

BAXTER, Alan. A concordância de número. In: LUCCHESI, Dante; BAXTER, Alan; RIBEIRO, Ilza (Org.). O Português Afro-Brasileiro, Salvador: EDUFBA, p. 269-293, 2009.

BRANDÃO, Sílvia Figueiredo. Concordância nominal. In: VIEIRA, Sílvia Rodrigues; BRANDÃO, Sílvia Figueiredo (Org.). Ensino de gramática: descrição e uso, São Paulo: Contexto, p. 57-83, 2011.

BRASIL. Constituição Federal de 1988. Promulgada em 5 de outubro de 1988. Disponível em: <http://www.planalto.gov.br/ccivil_03/constituicao/constituição.htm>.

BRASIL, Angela Varela. A repetição de hesitação no Português Xinguano. Papia, n. 9, p. 80-87, 1997. 
CHRISTINO, Beatriz. Definite articles in Huni-Kuin Portuguese. In: GOROVITZ, Sabine; MOZILLO, Izabella (Org.). Language contact: Mobility, Borders and Urbanization, Cambridge: Cambridge.

CHRISTINO, Beatriz. Apresentação a seção Línguas Indígenas em Contato. Papia, v. 25, n. 1, p. 41-45, 2015 a.

CHRISTINO, Beatriz. Gender agreement in Huni-Kuin Portuguese noun phrases. Papia, v. 25, n. 1, p. 77-102, 2015b.

CHRISTINO, Beatriz; LIMA E SILVA, Moana. Concordância verbal e nominal na escrita em Português Kaingang. Papia, v. 22, n. 2, 415-428, 2012.

EMMERICH, Charlotte. A língua de contato no alto Xingu. Origem, forma e função. Tese (Doutorado) - Universidade Federal do Rio de Janeiro, 1984.

FERREIRA, Marília. Descrição de aspectos da variante étnica usada pelos Parkatêjê. DELTA, v. 21, n. 1, p. 1-21, 2005.

FRANÇA, Aniela Improta. Comparação entre aquisição de Português e Inglês como L2. Papia, v. 9, p. 43-51, 1997.

GOMES, Christina Abreu. A importância do significado da preposição na aquisição de segunda língua. Papia, v. 9, p. 65-71, 1997.

GOMES, Christina Abreu. Processos variáveis e aquisição de preposição. In: RONCARATI, Claudia; MOLLICA, Maria Cecília (Org.). Variação e aquisição, Rio de Janeiro: Tempo Brasileiro, 1997a. p. 103-116,

GUY, Gregory R. Linguistic variation in Brazilian Portuguese: aspects of phonology, sintax and language history. Tese (Doutorado em Linguística) - University of Pennsylvania, Pennsylvania, 1981.

HOLM, John. Languages in contact: The partial restructuring of vernaculars. Cambridge: Cambridge, 2004.

LEMLE, Míriam; NARO, Anthony Julius. Competências básicas do português. Rio de Janeiro: Mobral/Fundação Ford, 1977.

LOPES, Lays de Oliveira Joel; SCHERRE, Martha Maria Pereira. Influência da saliência fônica no processo de concordância nominal no português falado na zona rural de Santa Leopoldina-ES. Anais do II CONEL, Vitória, 2014. p. 68-71.

LUCCHESI, Dante; MACEDO, Alzira. A variação na concordância de gênero no português de contato do Alto Xingu. Papia, v. 9, p. 20-36, 1997.
MACEDO, Alzira. Discourse markers in the Portuguese of the Upper Xingu. In: MOLLICA, Maria Cecilia; MARTELOTTA, Mário Eduardo (Org.). Análises linguísticas: a contribuição de Alzira Macedo. Rio de Janeiro: UFRJ, 2000.

MACEDO, Alzira. Pidginization and depidginization in the Portuguese of the Upper Xingu. In: MOLLICA, Maria Cecilia; MARTELOTTA, Mário Eduardo (Org.). Análises linguísticas: a contribuição de Alzira Macedo. Rio de Janeiro: UFRJ, 2000.

MAHER, Terezinha de Jesus Machado. Ser professor sendo índio: questões de língua(gem) e identidade. Tese (Doutorado) - Instituto de Estudos da Linguagem, Unicamp, 1996.

MAHER, Terezinha de Jesus Machado. Sendo índio em português... In: Signorini, Inês (Org.). Língua(gem) e identidade. Elementos para uma discussão no campo aplicado. Campinas: Mercado de Letras/Fapesp, 1998.

MAIA, Marcus. Uma mente, duas línguas: reflexões sobre a transferência de padrões de ordem vocabular em textos de falantes indígenas bilíngües. Cadernos de Educação Escolar Indígena - 3ograu indígena, v. 4, n. 1, p. 52-65, 2005.

MATTOS E SILVA, Rosa Virgínia. Língua Portuguesa: Novas fronteiras, velhos problemas. Revista Lusitana (Nova Série), v. 8, p. 5-21, 1987.

MATTOS E SILVA, Rosa Virgínia. Sete estudos sobre o português Kamayurá. Salvador: Centro Editorial e Didático da UFBa, 1988.

MEC/Secretaria de Educação Fundamental. Referencial Curricular Nacional para as Escolas Indígenas. Brasília, 1998.

MOLLICA, Maria Cecilia. Influência de substrato na aquisição de padrão fonológico de Português L2. Papia, v. 9, p. 37-42, 1997.

NARO, Anthony Julius; SCHERRE, Maria Marta Pereira. Mudança sem mudança: a concordância de número no Português Brasileiro. Scripta, v. 9, n. 18, p. 107-129, 2006.

OLIVEIRA, Josane Moreira de. A Sociolinguística Laboviana: Festejando o cinquentenário e planejando o futuro. Cadernos de Estudos Linguísticos, v. 58, n. 3, p. 481-501, 2016.

PAIVA, Maria da Conceição de. 1997. Hipofonologização no Português de Contato. Papia, v. 9, p. 52-64, 1997.

PETTER, Margarida; ZANONI, Dafne. Quilombos do Vale do Ribeira: variação e mudança na concordância de gênero e número. Papia, v. 15, p. 61-71, 2005.

ROMAINE, Suzanne. Bilingualism. Oxford: Blackwell, 1995. 
SCHERRE, Maria Marta Pereira. Reanálise da concordância nominal em português. Tese (Doutorado em Letras) - Universidade Federal do Rio de Janeiro, Rio de Janeiro, 1988.

SCHERRE, Maria Marta Pereira. Aspectos da concordância de número no Português do Brasil. Revista Internacional de Língua Portuguesa - Norma e Variação do Português. Associação das Universidades de Língua Portuguesa, v. 12, p. 37-49, 1994.

WINFORD, David. An introduction to contact linguistics. Oxford: Blackwell, 2003.

Recebido em 29/08/2016.

Aceito em $27 / 01 / 2017$ 